\title{
Anti-B7-H3 Antibody DS-5573a
}

National Cancer Institute

\section{Source}

National Cancer Institute. Anti-B7-H3 Antibody DS-5573a. NCI Thesaurus. Code C122924.

An antibody directed against the immunoregulatory protein B7-homologue 3 (B7-H3, CD276), with potential immunostimulating and antineoplastic activities. Upon intravenous administration, anti-B7-H3 antibody DS-5573a binds to the cell surface antigen B7-H3, thereby blocking B7-H3-mediated signaling. This abrog ates the inhibitory effect on T-cell activation and may activate the immune system to exert a cytotoxic T-lymphocyte (CTL) response against B7-H3-expressing tumor cells. B7-H3, a type I transmembrane protein and a member of the B7 co-stimulatory protein superfamily, is overexpressed on certain tumor cell types and on various immune cells. It is a negative regulator of the T-cell activation and and its overexpression plays a key role in tumor cell invasion and metastasis. 